Pacific Journal of Mathematic 


\title{
ON A PARTITION PROBLEM OF H.L. ALDER
}

\author{
GEORGE E. ANDREWS
}

\begin{abstract}
We study $\Delta_{d}(n)=q_{d}(n)-Q_{d}(n)$, where $q_{d}(n)$ is the number of partitions of $n$ into parts differing by at least $d$, and $Q_{d}(n)$ is the number of partitions of $n$ into parts congruent to 1 or $d+2(\bmod d+3)$. We prove that $\Delta_{d}(n) \rightarrow+\infty$ with $n$ for $d \geqq 4$, and that $\Delta_{d}(n) \geqq 0$ for all $n$ if $d=2^{s}-1, s \geqq 4$.
\end{abstract}

In 1956, H. L. Alder proposed the following problem [1].

"Let $q_{d}(n)=$ the number of partitions of $n$ into parts differing by at least $d$; let $Q_{d}(n)=$ the number of partitions of $n$ into parts congruent to 1 or $d+2\left(\bmod a^{2}+3\right)$; let $\Delta_{d}(n)=q_{d}(n)-Q_{d}(n)$. It is known that $\Delta_{1}(n)=0$ for all positive $n$ (Euler's identity), $\Delta_{2}(n)=0$ for all positive $n$ (one of the Rogers-Ramanujan identities), $\Delta_{3}(n) \geqq 0$ for all positive $n$ (from Schur's theorem which states $\Delta_{3}(n)=$ the number of those partitions of $n$ into parts differing by at least 3 which contain at least one pair of consecutive multiples of 3 ). (a) Is $\Delta_{d}(n) \geqq 0$ for all positive $d$ and $n$ ? (b) If (a) is true, can $\Delta_{d}(n)$ be characterized as the number of a certain type of restricted partitions of $n$ as is the case for $d=3$ ?"

This problem was again mentioned in $[2 ; \mathrm{p} .743]$ as still being open. A recent general result on partitions with difference conditions [3] allows us to give some partial answers to Alder's problem.

First we derive a partition theorem which is somewhat analogous to the type of result asked for by Alder.

THEOREM 1. Let $\nu$ be the largest integer such that $2^{\nu+1}-1 \leqq d$. Let $\mathscr{L}_{d}(n)$ denote the number of partitions of $n$ into distinct parts $\equiv 1,2,4, \cdots$, or $2^{2}(\bmod d)$. Then

$$
q_{d}(n) \geqq \mathscr{L}_{d}(n) .
$$

We may utilize some asymptotic formulae of Meinardus [4], [5] to prove

THEOREM 2 . For any $d \geqq 4, \lim _{n \rightarrow \infty} \Delta_{d}(n)=+\infty$

Finally, Theorem 1 may be utilized to prove a result which settles Alder's problem in an infinite number of cases

THEOREM 4. If $d=2^{s}-1$ and $s=1,2$, or $\geqq 4$, then $\Delta_{d}(n) \geqq 0$ for all $n$. 
The proof of Theorem 4 relies on the following result which is of independent interest.

TheOREM 3. Let $S=\left\{a_{i}\right\}_{i=1}^{\infty}$ and $T=\left\{b_{i}\right\}_{i=1}^{\infty}$ be two strictly increasing sequences of positive integers such that $b_{1}=1$ and $a_{i} \geqq b_{i}$ for all $i . \quad$ Let $\rho(S ; n)$ (resp. $\rho(T ; n)$ ) denote the number of partitions of $n$ into parts taken from $S$ (resp. $T$ ). Then

for all $n$.

$$
\rho(T ; n) \geqq \rho(S ; n)
$$

2. Proof of Theorem 1. In Theorem 1 of [3] set $N=d, a(1)=1$, $a(2)=2, \cdots, a(\nu+1)=2^{\nu}$. Thus in the notation of [3], $D\left(A_{N} ; n\right)$ becomes $\mathscr{L}_{d}(n)$. Now $D\left(A_{N} ; n\right)=E\left(A_{N}^{\prime} ; n\right)$ where the latter partition function is the number of partitions of $n$ :

$$
\begin{gathered}
n=b_{1}+b_{2}+\cdots+b_{s}, \\
b_{i} \equiv 1,2,3,4, \cdots, 2^{\nu+1}-1(\bmod d)
\end{gathered}
$$

with

$$
b_{i}-b_{i+1} \geqq d w\left(\beta_{d}\left(b_{i+1}\right)\right)+v\left(\beta_{d}\left(b_{i+1}\right)\right)-\beta_{d}\left(b_{i+1}\right) .
$$

Here $\beta_{d}(m)$ is the least positive residue of $m \bmod d, w(m)$ is the number of powers of 2 in the binary representation of $m$ and $v(m)$ is the least power of 2 in the binary representation of $m$. Consequently if $b_{i+1}$ $\equiv 2^{j}(\bmod d), 0 \leqq j \leqq \nu$,

$$
d w\left(\beta_{d}\left(b_{i+1}\right)\right)+v\left(\beta_{d}\left(b_{i+1}\right)\right)-\beta_{d}\left(b_{i+1}\right)=d \cdot 1+2^{j}-2^{j}=d .
$$

If $b_{i+1} \not \equiv 2^{j}(\bmod d) 0 \leqq j \leqq \nu$, then

$$
\begin{aligned}
d w\left(\beta_{d}\left(b_{i+1}\right)\right) & +v\left(\beta_{d}\left(b_{i+1}\right)\right)-\beta_{d}\left(b_{i+1}\right) \\
& \geqq 2 \cdot d+1-\left(2^{\nu+1}-1\right) \geqq 2 d+1-d=d+1 .
\end{aligned}
$$

Thus the difference condition is always $b_{i}-b_{i+1} \geqq d$ or stronger. Therefore $E\left(A_{N}^{\prime} ; n\right) \leqq q_{d}(n)$ and Theorem 1 follows.

3. Proof of Theorem 2. Meinardus has proved a general theorem on asymptotic formulae for partitions with repetitions [4]. Following the notation of Meinardus [4; pp. 388-389], we see that to treat $Q_{d}(n)$, we must have his

$$
a_{n}=\left\{\begin{array}{l}
1 \text { if } n \equiv 1, d+2(\bmod d+3) \\
0 \text { otherwise }
\end{array}\right.
$$

Under these circumstances, Meinardus's $D(s)$ satisfies

$$
D(s)=(d+3)^{-s}\left(\zeta\left(s, \frac{1}{d+3}\right)+\zeta\left(s, \frac{d+2}{d+3}\right)\right),
$$


where $\zeta(s, a)=\sum_{n=1}^{\infty}(n+a)^{-s}$, the Hurwitz zeta function [6; Ch. XIII], $\alpha$, the abscissa of convergence for $D(s)$ is 1 , and $A$, the residue at $s=1$ is $2 / d+3$.

$$
g(\tau)=\frac{e^{-\tau}+e^{-(d+2) \tau}}{1-e^{-(d+3) \tau}} .
$$

One may now easily verify that Meinardus's analytic conditions on $D(s)$ and $g(\tau)$ are fulfilled, thus

$$
\log Q_{d}(n) \sim 2 \pi \sqrt{\frac{n}{3 d+9}} .
$$

In [5], Meinardus has derived the asymptotic formula

$$
\log q_{d}(n) \sim 2 \sqrt{A_{d} n},
$$

where

$$
A_{d}=\frac{d}{2} \log ^{2} \alpha_{d}+\sum_{r=1}^{\infty} \frac{\left(\alpha_{d}\right)^{r d}}{r^{2}},
$$

and $\alpha_{d}$ is real $>0, \alpha_{d}^{d}+\alpha_{d}-1=0$.

If we put $\alpha_{d}=e^{-\lambda_{d}}$, so that $e^{-d \lambda_{d}}+e^{-\lambda_{d}}=1$, then

$$
\begin{aligned}
A_{d} & =\frac{d}{2} \lambda_{d}^{2}+\sum_{r=1}^{\infty} \frac{\alpha_{d}^{d \cdot r}}{r^{2}}>\frac{d}{2} \lambda_{d}^{2}+\alpha_{d}^{d} \\
& =\frac{d}{2} \lambda_{d}^{2}+1-e^{-\lambda_{d}}>\frac{d}{2} \lambda_{d}^{2}+\lambda_{d}-\frac{1}{2} \lambda_{d}^{2} \\
& =\frac{d-1}{2} \lambda_{d}^{2}+\lambda_{d} .
\end{aligned}
$$

Now the following table shows that

$$
A_{d}>\pi^{2} /(3 d+9) \text { for } 4 \leqq d \leqq 14
$$

TABLE 1.

\begin{tabular}{rllll}
\hline$d$ & $\lambda_{d}>$ & $\frac{d-1}{2} \lambda_{d}^{2}>$ & $A_{d}>$ & $\frac{\pi^{2}}{3 d+9}<$ \\
\hline 4 & 0.32 & 0.153 & 0.473 & 0.471 \\
5 & 0.28 & 0.15 & 0.43 & 0.42 \\
6 & 0.25 & 0.15 & 0.40 & 0.37 \\
7 & 0.22 & 0.14 & 0.36 & 0.33 \\
8 & 0.20 & 0.14 & 0.34 & 0.30 \\
9 & 0.19 & 0.14 & 0.33 & 0.28 \\
10 & 0.18 & 0.14 & 0.32 & 0.26 \\
11 & 0.16 & 0.12 & 0.28 & 0.24 \\
12 & 0.15 & 0.12 & 0.27 & 0.22 \\
13 & 0.15 & 0.13 & 0.28 & 0.21 \\
14 & 0.14 & 0.12 & 0.26 & 0.20 \\
\hline
\end{tabular}


For $d \geqq 15$, we have

$$
e^{-d(2 / d)}+e^{-2 / d}>e^{-2}+1-2 / d>1,
$$

Hence, $\lambda_{d}>2 / d$ and

$$
A_{d}>\frac{d-1}{2}\left(\frac{2}{d}\right)^{2}+2 / d=\frac{1}{d}(4-2 / d)>\frac{10}{3 d}>\frac{\pi^{2}}{3 d+9} .
$$

Thus for all $d \geqq 4$,

$$
A_{d}>\frac{\pi^{2}}{3 d+9}
$$

Hence comparing (3.1) with (3.2) we find

$$
\lim _{n \rightarrow \infty}\left(\log q_{d}(n)-\log Q_{d}(n)\right)=+\infty .
$$

Thus $\lim _{n \rightarrow \infty} \Delta_{d}(n)=\lim _{n \rightarrow \infty} q_{d}(n)\left(1-Q_{d}(n) / q_{d}(n)\right)=+\infty$. and we have Theorem 2.

I would like to thank the referee for aid in simplifying and extending Theorem 2.

4. Proof of Theorem 3. Let us define $S_{i}=\left\{a_{1}, a_{2}, \cdots a_{i}\right\}$ and $T_{i}=\left\{b_{1}, b_{2}, \cdots, b_{i}\right\}$. We shall proceed to prove by induction on $i$ that $\rho\left(T_{i} ; n\right) \geqq \rho\left(S_{i} ; n\right)$; this will establish Theorem 3 for if we choose $I$ such that $a_{I}>n, b_{I}>n$, then $\rho(T ; n)=\rho\left(T_{I} ; n\right) \geqq \rho\left(S_{I} ; n\right)=\rho(S ; n)$.

First we remark that $\rho\left(T_{i} ; n\right)$ is a nondecreasing function of $n$; this is because $1=b_{1} \in T_{i}$ and thus every partition of $n-1$ into parts taken from $T_{i}$ may be transformed into a partition of $n$ merely by adjoining a 1.

Now $\rho\left(T_{1} ; n\right)=1$ for all $n$ since $T_{1}=\{1\}$. Since $S_{1}=\left\{a_{1}\right\}$

$$
\rho\left(S_{1} ; n\right)= \begin{cases}1 & \text { if } a_{1} \mid n \\ 0 & \text { otherwise }\end{cases}
$$

Hence

$$
\rho\left(T_{1} ; n\right) \geqq \rho\left(S_{1} ; n\right) .
$$

Now assume that $\rho\left(T_{i-1} ; n\right) \geqq \rho\left(S_{i-1} ; n\right)$ for all $n$. Hence if we define $\rho\left(T_{i} ; 0\right)=\rho\left(S_{i} ; 0\right)=1$,

$$
\begin{aligned}
\sum_{n=0}^{\infty} & \left(\rho\left(T_{i} ; n\right)-\rho\left(S_{i} ; n\right)\right) q^{n} \\
& =\prod_{j=1}^{i} \frac{1}{1-q^{b_{j}}}-\prod_{j=1}^{i} \frac{1}{1-q^{a_{j}}} \\
& =\left(\prod_{j=1}^{i-1} \frac{1}{1-q^{b_{j}}}\right)\left(\frac{1}{1-q^{a_{i}}}+\frac{q^{b_{i}}-q^{a_{i}}}{\left(1-q^{a_{i}}\right)\left(1-q^{b_{i}}\right)}\right)-\prod_{j=1}^{i} \frac{1}{1-q^{a_{j}}}
\end{aligned}
$$




$$
\begin{aligned}
= & \frac{1}{1-q^{a_{i}}}\left(\prod_{j=1}^{i-1} \frac{1}{1-q^{b_{j}}}-\prod_{j=1}^{i-1} \frac{1}{1-q^{a_{j}}}\right)+\frac{q^{b_{i}}-q^{a_{i}}}{\left(1-q^{a_{i}}\right)} \prod_{j=1}^{i} \frac{1}{1-q^{b_{j}}} \\
= & \frac{1}{1-q^{a_{i}}}\left(\sum_{n=0}^{\infty}\left(\rho\left(T_{i-1} ; n\right)-\rho\left(S_{i-1} ; n\right)\right) q^{n}\right. \\
& \left.+\sum_{n=0}^{\infty}\left(\rho\left(T_{i} ; n-b_{i}\right)-\rho\left(T_{i} ; n-a_{i}\right)\right) q^{n}\right) .
\end{aligned}
$$

Now the coefficients of these two infinite series are nonnegative: the first by the induction hypothesis, and the second by the fact that $\rho\left(T_{i} ; n\right)$ is a nondecreasing sequence. Since $\left(1-q^{a_{i}}\right)^{-1}=\sum_{j=0}^{\infty} q^{j a_{i}}$, we see- that all coefficients in the power series expansion of our last expression must be nonnegative. Hence

$$
\rho\left(T_{i} ; n\right) \geqq \rho\left(S_{i} ; n\right),
$$

and Theorem 3 is proved.

5. Proof of Theorem 4. Since $d=2^{s}-1$, we see that the $\nu$ of Theorem 1 is just $s-1$. Now

$$
\begin{aligned}
\sum_{n=0}^{\infty} & \mathscr{L}_{d}(n) q^{n}=\prod_{j=0}^{\infty}\left(1+q^{d j+1}\right)\left(1+q^{d j+2}\right) \cdots\left(1+q^{d j+2^{\nu}}\right) \\
& =\prod_{j=0}^{\infty} \frac{1}{\left(1-q^{2 d j+1}\right)\left(1-q^{2 d j+d+2}\right)\left(1-q^{2 d j+d+4}\right) \cdots\left(1-q^{2 d j+d+2^{\nu}}\right)} .
\end{aligned}
$$

Thus $\mathscr{L}_{d}(n)=\rho(T ; n)$ where $T=\{m \mid m \equiv 1, d+2, d+4, \cdots$, or $\left.d+2^{s-1}(\bmod 2 d)\right\}$. Clearly, $1 \in T$. We now show that for $s \geqq 4$ the $i^{\text {th }}$ element of $T$ (arranged in increasing magnitude) is no larger than the $i^{\text {th }}$ element of $S$ where $S=\{m \mid m \equiv 1, d+2(\bmod d+3)\}$. Since $s \geqq 4$, the first four elements of $T$ are

$$
1, d+2, d+4, d+8(2 d+5>d+8 \text { since } d \geqq 15) .
$$

Thus the first four elements of $T$ are less than or equal the first four elements of $S$ respectively. In general the $(4 m+1)-s t$ element of $T$ is $\leqq 2 d m+1$ while the $(4 m+1)-s t$ element of $S$ is $2 m(d+3)+1$; for $2 \leqq j \leqq 4$ the $(4 m+j)-$ th element of $T$ is $\leqq 2 d m+d+2^{j-1}$ while the $(4 m+j)$ - element of $S$ is $\geqq 2 m(d+3)+d+2$ and for $2 \leqq j \leqq 4, m \geqq 1,2 d m+d+2^{j-1} \leqq 2 d m+d+8 \leqq 2 d m+d+6+2 \leqq$ $2 m(d+3)+d+2$. Hence, the conditions of Theorem 3 are met, and therefore

$$
q_{d}(n) \geqq \mathscr{L}_{d}(n)=\rho(T ; n) \geqq \rho(S ; n)=Q_{d}(n) .
$$

Thus Theorem 4 is established.

6. Conclusion. By modification of the results in [3], it appears possible to apply the techniques of $\S 4$ to prove that $\Delta_{d}(n) \geqq 0$ for 
any $d \geqq 15$ which is a difference of powers of 2 ; however, since this approach does not yield a complete answer to Alder's problem it seems hardly worth undertaking.

Lengthier versions of the following table indicate that Alder's problem may be extended as follows.

Conjecture. $\Delta_{d}(n)>0$ for $n \geqq d+6$ if $d \geqq 8$.

\begin{tabular}{rcccccc}
\hline$n$ & $\Delta_{3}(n)$ & $\Delta_{4}(n)$ & $\Delta_{5}(n)$ & $\Delta_{6}(n)$ & $\Delta_{7}(n)$ & $\Delta_{8}(n)$ \\
\hline 1 & 0 & 0 & 0 & 0 & 0 & 0 \\
2 & 0 & 0 & 0 & 0 & 0 & 0 \\
3 & 0 & 0 & 0 & 0 & 0 & 0 \\
4 & 0 & 0 & 0 & 0 & 0 & 0 \\
5 & 0 & 0 & 0 & 0 & 0 & 0 \\
6 & 0 & 0 & 0 & 0 & 0 & 0 \\
7 & 0 & 0 & 0 & 0 & 0 & 0 \\
8 & 0 & 0 & 0 & 0 & 0 & 0 \\
9 & 1 & 0 & 0 & 0 & 0 & 0 \\
10 & 0 & 1 & 0 & 0 & 0 & 0 \\
11 & 0 & 1 & 1 & 0 & 0 & 0 \\
12 & 0 & 1 & 1 & 1 & 0 & 0 \\
13 & 0 & 0 & 2 & 1 & 1 & 0 \\
14 & 0 & 0 & 1 & 2 & 1 & 1 \\
15 & 1 & 0 & 1 & 2 & 2 & 1 \\
16 & 1 & 0 & 0 & 2 & 2 & 2 \\
17 & 1 & 1 & 0 & 1 & 3 & 2 \\
18 & 1 & 2 & 0 & 1 & 2 & 3 \\
19 & 1 & 2 & 1 & 0 & 2 & 3 \\
20 & 1 & 2 & 2 & 0 & 1 & 3 \\
21 & 2 & 2 & 3 & 1 & 1 & 2 \\
22 & 2 & 2 & 3 & 2 & 0 & 2 \\
23 & 2 & 3 & 3 & 3 & 1 & 1 \\
24 & 2 & 4 & 3 & 4 & 2 & 1 \\
\hline
\end{tabular}

\section{REFERENCES}

1. H. L. Alder, Research problem no. 4, Bull. Amer. Math. Soc. 62 (1956), 76.

2. - Partition identities-from Euler to the present, Amer. Math. Monthly 76 (1969), 733-746.

3. G. E. Andrews, A general theorem on partitions with difference conditions, Amer.

J. Math. 91 (1969), 18-24.

4. G. Meinardus, Asymptotische Aussagen über Partitionen, Math. Zeit. 59 (1954), 388-398.

5. - Uber Partitionen mit Differenzenbedingungen, Math. Zeit. 61 (1954), 289-302.

6. E. T. Whittaker and G. N. Watson, Modern Analysis, 4th Ed., Cambridge University Press, Cambridge, 1927.

Received April 1, 1970. Partially supported by NSF Grant GP-9660. 


\section{PACIFIC JOURNAL OF MATHEMATICS}

\section{EDITORS}

H. SAMELson

Stanford University

Stanford, California 94305

R. R. PHelPS

University of Washington

Seattle, Washington 98105
J. Dugundu

Department of Mathematics

University of Southern Californle

Los Angeles, California 9.0007

RICHARD ARENS

University of California

Los Angeles, California 9.0024

\section{ASSOCIATE EDITORS}
E. F. BECKENBACH
B. H. NeumanN
F. WOLE
K. Yoshida

\section{SUPPORTING INSTITUTIONS}

UNIVERSITY OF BRITISH COLUMBIA

CALIFORNIA INSTITUTE OF TECHNOLOGY

UNIVERSITY OF CALIFORNIA

MONTANA STATE UNIVERSITY

UNIVERSITY OF NEVADA

NEW MEXICO STATE UNIVERSITY

OREGON STATE UNIVERSITY

UNIVERSITY OF OREGON

OSAKA UNIVERSITY

UNIVERSITY OF SOUTHERN CALIFORNIA

\author{
STANFORD UNIVERSITY \\ UNIVERSITY OF TOKYO \\ UNIVERSITY OF UTAH \\ WASHINGTON STATE UNIVERSITY \\ UNIVERSITY OF WASHINGTON \\ AMERICAN MATHEMATICAL SOCIETY \\ CHEVRON RESEARCH CORPORATION \\ NAVAL WEAPONS CENTER
}

The Supporting Institutions listed above contribute to the cost of publication of this Journal, but they are not owners or publishers and have no responsibility for its content or policies.

Mathematical papers intended for publication in the Pacific Journal of Mathematics should be in typed form or offset-reproduced, (not dittoed), double spaced with large margins. Underline Greek letters in red, German in green, and script in blue. The first paragraph or two must be capable of being used separately as a synopsis of the entire paper. The editorial "we" must not be used in the synopsis, and items of the bibliography should not be cited there unless absolutely necessary, in which case they must be identified by author and Journal, rather than by item number. Manuscripts, in duplicate if possible, may be sent to any one of the four editors. Please classify according to the scheme of Math. Rev. Index to Vol. 39. All other communications to the editors should be addressed to the managing editor, Richard Arens, University of California, Los Angeles, California, 90024.

50 reprints are provided free for each article; additional copies may be obtained at cost in multiples of 50 .

The Pacific Journal of Mathematics is published monthly. Effective with Volume 16 the price per volume (3 numbers) is $\$ 8.00$; single issues, $\$ 3.00$. Special price for current issues to individual faculty members of supporting institutions and to individual members of the American Mathematical Society: $\$ 4.00$ per volume; single issues $\$ 1.50$. Back numbers are available.

Subscriptions, orders for back numbers, and changes of address should be sent to Pacific Journal of Mathematics, 103 Highland Boulevard, Berkeley, California, 94708.

PUBLISHED BY PACIFIC JOURNAL OF MATHEMATICS, A NON-PROFIT CORPORATION

Printed at Kokusai Bunken Insatsusha (International Academic Printing Co., Ltd.), 7-17, Fujimi 2-chome, Chiyoda-ku, Tokyo, Japan. 


\section{Pacific Journal of Mathematics}

\section{Vol. 36, No. 2 December, 1971}

George E. Andrews, On a partition problem of H. L. Alder ............ 279

Thomas Craig Brown, An interesting combinatorial method in the theory of locally finite semigroups .......................... 285

Yuen-Kwok Chan, A constructive proof of Sard's theorem ............. 291

Charles Vernon Coffman, Spectral theory of monotone Hammerstein

operators...................................... 303

Edward Dewey Davis, Regular sequences and minimal bases .......... 323

Israel (Yitzchak) Nathan Herstein and Lance W. Small, Regular elements in

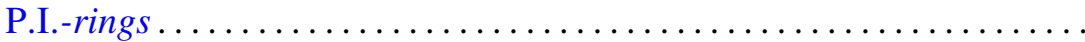

Marcel Herzog, Intersections of nilpotent Hall subgroups ..............

W. N. Hudson, Volterra transformations of the Wiener measure on the space

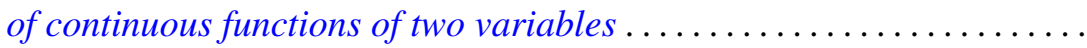

J. H. V. Hunt, An n-arc theorem for Peano spaces ................ 351

Arnold Joseph Insel, A decomposition theorem for topological group

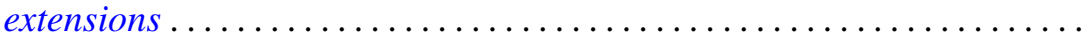

Caulton Lee Irwin, Inverting operators for singular boundary value

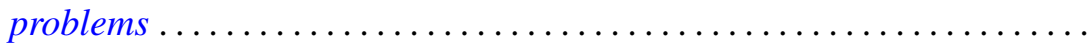

Abraham A. Klein, Matrix rings of finite degree of nilpotency ............ 387

Wei-Eihn Kuan, On the hyperplane section through a rational point of an algebraic variety...

John Hathway Lindsey, II, On a six-dimensional projective representation of $\mathrm{PSU}_{4}(3)$

Jorge Martinez, Approximation by archimedean lattice cones ...

J. F. McClendon, On stable fiber space obstructions .........

Mitsuru Nakai and Leo Sario, Behavior of Green lines at the Kuramochi boundary of a Riemann surface ....................

Donald Steven Passman, Linear identities in group rings. I. .

Donald Steven Passman, Linear identities in group rings. II ...

David S. Promislow, The Kakutani theorem for tensor products of

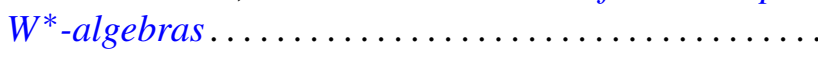

Richard Lewis Roth, On the conjugating representation of a finite group

Bert Alan Taylor, On weighted polynomial approximation of entire functions...

William Charles Waterhouse, Divisor classes in pseudo Galois

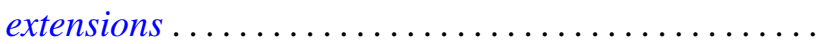

Chi Song Wong, Subadditive functions ...

Ta-Sun $\mathrm{Wu}$, A note on the minimality of certain bitransformation groups 